\title{
Jefferson accelerator will seek to pin down quark theory
}

Newport News, Virginia. The world's most powerful electron microscope was inaugurated by Hazel O'Leary, the US energy secretary, last week, enabling physicists to probe the structure of the nucleus and improve their understanding of the nature and function of quarks.

Completion of the $\$ 600$ million Continuous Electron Beam Accelerator Facility (CEBAF) on a green-field site in the Naval shipyard town of Newport News marks a considerable triumph for Hermann Grunder, the project director, who took control of the project in 1985 . Grunder radically altered its design to incorporate superconducting technology, while at the same time maintaining the political support needed to keep the project on track.

In a robust dedication speech last Friday (24 May), Grunder told his audience of 2,000 staff and invited guests that "times were too easy" when CEBAF got started. "Let me assure you that they're going to get tougher," he said. "We must do a better job of thanking our friends and obstructing our enemies."

CEBAF, which is managed by a specially created consortium of 41 universities in the southern United States, is already a success in one important sense. The South traditionally fares badly in terms of attracting federal science funds and their associated industrial spin-off. But CEBAF

\section{-emerging diseases division.}

But it still remains difficult to answer critics who argue that the best available scientific advice may not adequately predict future situations, concedes Howard Rees, chairman of the OIE's Code of Commission, and a former UK chief veterinary officer. "We can't say what will happen in ten years time," he admits. "We can only base our decisions on current knowledge; if something new comes along then we have to reconsider."

Germany feels, for example, that the UK government's belated acknowledgement of a possible link between BSE and CJD vindicates its demands since the beginning of the BSE epidemic in the 1980s for stricter precautionary measures to be taken. It is now acknowledged, for example, that the UK's 1989 ban on the use of cattle and sheep offal in feed for these animals was inadequate, in that it stopped short of prohibiting the feeding of offal to any farm animal.

Despite the ban, around 28,000 UK cattle have since become infected, mainly because they ate feed that had been contaminated with pig and poultry feed containing cattle and sheep offal. Only in March this year did the United Kingdom introduce a comprehensive ban on the use of offal in feed for all farm animals. A meeting of the OIE expert group on BSE concluded earlier this month that the new ban has already led to the creation of 127 new faculty positions at the 41 participating universities, more than doubling their strength in nuclear physics.

Experiments have been carried out at the facility since last November, when it began firing its continuous beam of electrons at an energy of $4 \mathrm{GeV}$ into stationary targets in one of its three underground target halls. Nearly 550 scientists from more than a hundred institutions will use the beam over the next year, probing nuclei to improve their understanding of how quarks build up the nucleus.

Their experiments will help to verify and refine the theory of quantum chromodynamics $(Q C D)$, which defines the 'strong force' holding nuclei together, in a manner analogous to that in which atomic physicists in the 1930s used experimentation to refine quantum electrodynamics (QED).

“Until now, we haven't had a sound scientific basis for understanding the nucleus," says Nathan Isgur, head of theory at CEBAF. Experiments at CEBAF will concentrate at first on the study of the simplest nuclei - deuterium, tritium, helium-3 and helium-4 - as the interactions of protons and neutrons in larger nuclei become alarmingly complicated.

Other electron accelerators, such as that at the Stanford Linear Accelerator Center in California, have delivered short

means that now "there should be no risk of infection from feed". Critics ask why such action was not taken sooner.

Suspicion of scientific advice is also being fuelled by the apparent emphasis of British politicians and government scientists in the past on trying to prove the negative case: that BSE could not pass to humans and cause CJD. As a result, much of the public now distrusts messages from scientists, who are seen - despite the caveats of some - to have been excessively reassuring.

Indeed, current research into the possible transmission of BSE to humans remains poorly geared to producing answers relevant to public health, according to Annick Alperovitch, head of the French CJD surveillance network and a member of the French and WHO expert committees on BSE/CJD.

Assurances about the safety of eating beef rely too much on experimental data, she says, whereas levels of infection that were so low as to be undetectable in such experiments could still create an epidemic, given the very large numbers of people who may have been exposed.

Similarly, while the $\mathrm{WHO}$ and other organizations point out that muscle tissue (beef) has never been shown to be infective, Alperovitch argues that this does not guarantee that infection might not occur under abattoir conditions, for example, through pulses of electrons, enabling physicists to study a few events at a time. In contrast, the continuous beam at CEBAF will permit the statistical study of hundreds of thousands of collisions every second. A veritable mountain of data will result: in Isgur's analogy, the 300 terabytes produced each year is equivalent to a detailed biography for every human being on Earth.

Roy Holt of the University of Illinois carried out one of the first experiments at CEBAF last November, using the beam to create $\gamma$ rays with which to split the simplest nucleus - the proton and neutron pair that make up deuterium. Don Geesaman of the Argonne National Laboratory in Illinois set up another experiment, studying the probability that a proton dislodged from a large nucleus will actually pass through it and escape.

During its battle for funding, CEBAF was dubbed the "Warnertron" in honour of Senator John Warner (Republican, Virginia), one of the project's most vigorous patrons, who attended last week's inauguration. Hazel O'Leary, who comes from Newport News, may have been sorely tempted to name it after herself. But she named it the Thomas Jefferson National Accelerator Facility, in memory of the only US president ever to declare that "politics is my duty, but science is my passion".

Colin Macilwain

contamination of beef by other tissues. The difficulty in extrapolating experimental data to the real world explains some of the divergent opinions among experts, she says.

It is important to recognize that science cannot provide certainties within the timescale demanded by politicians and the beef industry, says Alperovitch. "It is important to wait", she says, until epidemiological and other animal experiments clarify the situation towards the end of the year. In the interim period, expert committees will need to steer a course between reasonable precaution and over-reaction.

Whatever the scientific uncertainty about the links between BSE and CJD, many remain convinced that a return to using scientific advice in decision-making provides the only way out of the beef crisis. "My plea is to use more science," says Rees. "It is the only way we can get some rational decisions on this; with politics you don't get rational decisions."

But Rees also agrees that the ban on British beef is unlikely to be lifted soon. Irrespective of what scientific assurances are given as to beef's safety, what many European governments will retain is the hard fact that BSE is still widely present in British herds. They are likely to argue that a reasonable time to lift the ban will be when the UK government has eliminated the disease completely.

Declan Butler 